\title{
Brain Angiotensin-II-derived Reactive Oxygen Species: Implications for High Blood Pressure
}

Alynne S. Carvalho, Drielle D. Guimaraes, Bruna P. V. Dantas, Juliana N. Carreiro, Leonidas G. Mendes-Junior, Maria S. França-Silva, Matheus M.O. Monteiro, Naiane F.B. Alves, Suênia K.P. Porpino,Thyago M. Queiroz and Valdir A. Braga*

Biotechnology Center, Federal University of Paraiba, João Pessoa, PB, Brazil

\begin{abstract}
Hypertension and its relation to free radicals have been matter of continuous research worldwide. This review is based on the premise that some forms of neurogenic hypertension is, in part, caused by the formation of AngiotensinII (Ang II)-derived reactive oxygen species within the brain, especially in areas along the Subfornical OrganParaventricular Nucleus of the Hypothalamus-Rostral Ventrolateral Medulla pathway (SFO-PVN-RVLM pathway). Here we will discuss the recent contribution of our laboratory and others regarding the mechanisms by which neurons in the Rostral Ventrolateral Medulla (RVLM) are activated by Ang II, how they communicate with the SFO and PVN and more importantly, how Ang II-derived Reactive Oxygen Species (ROS) participate along the SFO-PVN-RVLM pathway in the pathogenesis of neurogenic hypertension.
\end{abstract}

Keywords: Superoxide; Sympathetic; Angiotensin; Subfornical organ; Rostral ventrolateral medulla

\section{Introduction}

The mechanisms underlying neurogenic hypertension have been matter of continuous research worldwide. This review focus on the hypothesis that neurogenic hypertension is, in part, caused by the formation of Angiotensin-II (Ang II)-derived reactive oxygen species in key cardiovascular nuclei, especially in the Rostral Ventrolateral Medulla (RVLM).

Ang II is the major effector of the Renin-Angiotensin-Aldosterone System (RAAS). This system consists mainly of a 2-step enzymatic cascade catalyzed by renin and Angiotensin-Converting Enzyme (ACE), generating Ang II [1], the effect of Ang II is mediated by Ang II receptors. Two isoforms of Ang II receptor have been identified: type 1 receptor (AT1R) and type 2 receptor (AT2R). In general, it is accepted that cardiovascular effects of Ang II such as vasoconstriction, regulation of fluid and drinking behavior are ascribed to AT1R. Besides, AT1R is involved in the progression of cardiovascular diseases including hypertension, atherosclerosis, cardiac hypertrophy and heart failure $[2,3]$

An additional component of the RAAS family, angiotensinconverting enzyme2 (ACE2) cleaves Ang I and Ang II into Ang 1-9 and Ang 1-7, respectively [4]. Studies show that ACE2 promotes beneficial effects, such as important in vasodilatation, natriuresis and to inhibit heart failure. These effects seems to be related with inhibition of oxidative stress, since ACE2 deficiency leads to an Ang II-mediated activation of the NADPH oxidase system and exacerbated oxidative stress leading to hypertension $[4,5]$. Abundant evidence now points to oxidative stress as a key mechanism in Ang II-dependent neurogenic hypertension [6,7]. Furthermore, it has become evident that reactive oxygen species are important in the increase in blood pressure elicited by Ang II administered peripherally or directly in the Central Nervous System (CNS). However, considering that Ang II is composed by eight amino acids, which makes it incapable of crossing the Blood Brain Barrier (BBB), the mechanisms underlying how circulating Ang II acts within the brain to eventually modulate sympathetic activity and induce hypertension remain unknown. The most accepted hypothesis is that angiotensin II, as any other circulating lipophobic substance, acts on neurons in specialized regions of the brain known as the
Circumventricular Organs (CVOs), which partially lack the normal $\mathrm{BBB}$, in order to alter the function of other brain regions protected by this important barrier that "filters" what enters the CNS. As a result, activation of the CVOs triggers the local production of Ang II in brain areas protected by BBB, mainly the RVLM, which in turn alters sympathetic drive. Here we will discuss the recent advances regarding the mechanisms by which neurons in the RVLM are activated by Ang II/ROS and how Ang II-derived reactive oxygen species participate along the SFO-PVN-RVLM pathway in the context of neurogenic hypertension.

\section{Reactive Oxygen Species in the Brain}

The pathways for production of reactive oxygen species in mammalian cells have been revised elsewhere [8]. The first evidence that Ang II activates NADPH oxidase in vascular smooth muscle cells to produce ROS was presented by Griendling and colleagues [9]. More recently, accumulating evidence from our laboratory and others suggest that, like vascular cells, neurons also require ROS to carry out crucial functions related to central control of blood pressure [10-15].

There is compelling evidence that superoxide anion is necessary to elicit the vasopressor, bradycardic, and dipsogenic responses produced by intracerebroventricular (ICV) administration of Ang II in conscious mice [16]. It has also been shown that Ang II causes robust increases in superoxide production in cultured SFO neurons. In addition, adenoviral-mediated delivery of cytoplasmically targeted superoxide dismutase (SOD) selectively to the SFO abolishes the cardiovascular and dipsogenic actions of Ang II in normotensive mice and prevents

*Corresponding author: Valdir Andrade Braga, PhD, Biotechnology Center Federal University of Paraiba, Caixa Postal 5009, 58.051-970, João Pessoa, PB, Brazil, Tel: (55) 833216 7511; E-mail: valdir@cbiotec.ufpb.br

Received May 22, 2012; Accepted July 24, 2012; Published July 26, 2012

Citation: Carvalho AS, Guimaraes DD, Dantas BPV, Carreiro JN, MendesJunior LG, et al. (2012) Brain Angiotensin-II-derived Reactive Oxygen Species: Implications for High Blood Pressure. J Hypertens 1:107. doi:10.4172/21671095.1000107

Copyright: (c) 2012 Carvalho AS, et al. This is an open-access article distributed under the terms of the Creative Commons Attribution License, which permits unrestricted use, distribution, and reproduction in any medium, provided the original author and source are credited. 
the hypertension in chronic peripheral Ang II infused mice [10,16]. Moreover, adenoviral vectors encoding small interfering RNA to selectively silence Nox 2 or Nox4 (two isoforms of the NADPH oxidase) expression in the subfornical organ demonstrate that both Nox2 and Nox4 are required for the full vasopressor effects of brain Ang II [17,18]. One possible downstream mechanism of the activation of AT1R in the SFO and subsequent production of ROS is the superoxide-mediated intracellular calcium influx observed in neuroblastoma Neuro-2A cells, which is inhibited by the adenoviral-mediated expression of a dominant-negative isoform of Rac1 (AdN17Rac1), a critical component for NADPH oxidase activation and superoxide production. These evidences suggest that increased intracellular superoxide production in the SFO is critical in the development of neurogenic hypertension by increasing in sympathetic outflow via RVLM activation.

\section{Reactive Oxygen Species in the Rostral Ventrolateral Medulla}

The RVLM is a brainstem region that contains bulbospinal neurons providing a major input to the preganglionic neurons of the sympathetic nervous system $[19,20]$. The importance of the RVLM for maintaining blood pressure in anesthetized animals had first been documented 130 years ago [21]. However, only after the pioneer studies performed by Guertzenstein and colleagues [22] suggesting that supraspinal sympathetic vasomotor drive originates from the RVLM that truly brought researcher's attention to this brainstem area [22,23].

The RVLM receives inputs from the SFO and the PVN as discussed earlier in this review, forming the so called SFO-PVN-RVLM pathway, where Ang II seems to be the key neurotransmitter. For instance, immunohistochemistry studies showing Ang II-like immunoreactive neurons in PVN and terminals in RVLM support the concept that angiotensinergic neurons in the PVN innervate the RVLM [24]. Of note, angiotensin receptors, mainly AT1R subtype, are also present in the RVLM [25] and plays an important role in altering the activity of RVLM neurons [26]. For example, injection of Ang II into the RVLM of the cat produces pressor response [27]. In addition, pharmacological blockade of AT1R attenuates the pressor response to Ang II microinjection in the RVLM of rats [28]. Furthermore, microinjection of losartan in the RVLM attenuates the pressor response produced by peripheral chemoreflex activation [13].

In experimental models of hypertension, the actions of Ang II seem to be enhanced and AT1R seem to be tonically stimulated. In the Spontaneously Hypertensive Rat (SHR), for example, it has been shown that injection of Ang II in the RVLM produces a significantly greater increase in blood pressure in SHR compared to normotensive rats [29]. Additionally, candesartan and valsartan, AT1R antagonists, injected in the RVLM decreased blood pressure in SHR to normotensive levels but had no effect in normotensive rats [29].

Regarding reactive oxygen species in the RVLM, our laboratory and others have shown that Ang II-derived superoxide anions accumulation in the RVLM is critical for the pathogenesis of neurogenic hypertension (Figure 1) [12,17,18,30-32]. The increase of superoxide anions leads to changes in ion channels, particularly calcium and potassium channels, altering neuronal properties in RVLM resulting in increase in sympathetic nerve activity and increase in blood pressure [33]. To date, we have shown that chronic peripheral Ang II infusion in mice produces a slow developing hypertension, which is accompanied of superoxide accumulation in the RVLM and increased sympathetic activity [30]. Similar results have been found in $2 \mathrm{~K} 1 \mathrm{C}$ rats [31]. Interestingly, scavenging of superoxide by adenovirus-mediated

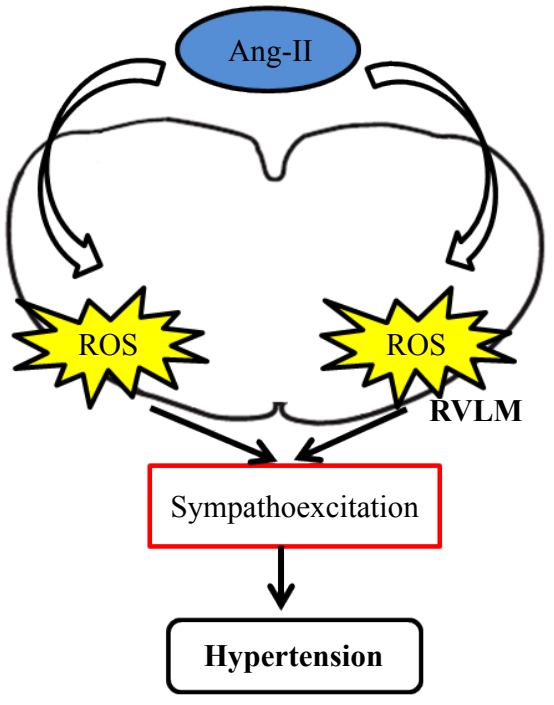

Figure 1: Scheme showing the mechanism by which angiotensin II induces the increase of ROS in the rostral ventrolateral medulla (RVLM) and modulate the sympathetic flow leading to hypertension.

overexpression of Copper/Zinc Superoxide Dismutase (CuZnSOD) in the RVLM prevents both the accumulation of superoxide and the increase in sympathetic activity. Of note, we demonstrated in rats that the association of dietary salt to Ang II infusion potentiates the superoxide accumulation in the RVLM and the increase in sympathetic activity caused by Ang II alone [12]. Furthermore, we demonstrated that selective ablation of the AT1R in the RVLM using the loxP-Crerecombinase technique also prevented hypertension and superoxide accumulation in the RVLM of Ang II infused mice [30].

In addition to superoxide accumulation in the RVLM, it has been documented that AT-1 mRNA expression and $\mathrm{NAD}(\mathrm{P}) \mathrm{H}$ oxidase subunits are greater in the RVLM and PVN of $2 \mathrm{~K}-1 \mathrm{C}$ rats when compared to their sham control group, while the CuZnSOD expression remains. Furthermore, injection of tempolinto the RVLM reduced blood pressure and renal sympathetic activity in $2 \mathrm{~K} 1 \mathrm{C}$ but not in sham rats unchanged [33].

Oxidative stress in the RVLM has also been associated to the pathogenesis of the hypertension observed in chronic renal failure. For instance, rats with chronic renal failure show increased $\mathrm{p} 47$ phox and gp91phox mRNA expression in the RVLM associated to a reduction of AT1 mRNA in the brainstem compared to their controls [34].

\section{Conclusions}

Although the basic research using laboratory animals has considerably contributed to unraveling the mechanisms underlying the role of reactive oxygen species in the pathogenesis of hypertension, its translation towards the human benefit is still matter of debate, mainly because some clinical trials have failed in documenting the benefits of antioxidant therapies [35]. Therefore, the challenge for the next decades will be finding a path to safely interfere with reactive oxygen species inside the human's brain, especially in hypertensive patients, in order to prove the benefits of local antioxidant therapy as a reliable treatment for neurogenic hypertension. 
Citation: Carvalho AS, Guimaraes DD, Dantas BPV, Carreiro JN, Mendes-Junior LG, et al. (2012) Brain Angiotensin-II-derived Reactive Oxygen Species: Implications for High Blood Pressure. J Hypertens 1:107. doi:10.4172/2167-1095.1000107

\section{References}

1. Abadir PM (2011) The frail renin-angiotensin system. Clin Geriatr Med 27: 5365.

2. Stegbauer J, Coffman TM (2011) New insights into angiotensin receptor actions: from blood pressure to aging. Curr Opin Nephrol Hypertens 20: 84-88.

3. Ichiki T, Miyazaki R, Kamiharaguchi A, Hashimoto T, Matsuura H, et al. (2012) Resveratrol attenuates angiotensin II-induced senescence of vascular smooth muscle cells. Regul Pept 177: 35-39.

4. Chang SY, Chen YW, Chenier I, Tran Sle M, Zhang SL (2011) Angiotensin II type II receptor deficiency accelerates the development of nephropathy in type I diabetes via oxidative stress and ACE2. Exp Diabetes Res 2011: 521076.

5. Bodiga S, Zhong JC, Wang W, Basu R, Lo J, et al. (2011) Enhanced susceptibility to biomechanical stress in ACE2 null mice is prevented by loss of the p47(phox) NADPH oxidase subunit. Cardiovasc Res 91: 151-161.

6. Houston MC (2005) Nutraceuticals, vitamins, antioxidants, and minerals in the prevention and treatment of hypertension. Prog Cardiovasc Dis 47: 396-449.

7. Kitiyakara C, Wilcox CS (1998) Antioxidants for hypertension. Curr Opin Nephrol Hypertens 7: 531-538.

8. Harrison DG, Dikalov S (2006) Oxidative events in cell and vascular biology. Molecular mechanisms in hypertension.1st edition. Abingdon (UK): Taylor \&Francis Medical Books 297-320.

9. Griendling KK, Minieri CA, Ollerenshaw JD, Alexander RW (1994) Angiotensin II stimulates $\mathrm{NADH}$ and $\mathrm{NADPH}$ oxidase activity in cultured vascular smooth muscle cells. Circ Res 74: 1141-1148.

10. Zimmerman MC, Lazartigues E, Lang JA, Sinnayah P, Ahmad IM, et al. (2002) Superoxide mediates the actions of angiotensin II in the central nervous system. Circ Res 91: 1038-1045.

11. Zimmerman MC, Davisson RL (2004) Redox signaling in central neural regulation of cardiovascular function. Prog Biophys Mol Biol 84: 125-149.

12. Braga VA (2010) Dietary salt enhances angiotensin-II-induced superoxide formation in the rostral ventrolateral medulla. Auton Neurosci 155: 14-18.

13. Nunes FC, Ribeiro TP, França-Silva MS, Medeiros IA, Braga VA (2010) Superoxide scavenging in the rostral ventrolateral medulla blunts the pressor response to peripheral chemoreflex activation. Brain Res 1351: 141-149.

14. Giusti MF, Sato MA, Cardoso LM, Braga VA, Colombari E (2011) Central antioxidant therapy inhibits parasympathetic baroreflex control in conscious rats. Neurosci Lett 489: 115-118.

15. Botelho-Ono MS, Pina HV, Sousa KH, Nunes FC, Medeiros IA, et al. (2011) Acute superoxide scavenging restores depressed baroreflex sensitivity in renovascular hypertensive rats. Auton Neurosci 159: 38-44.

16. Zimmerman MC, Lazartigues E, Sharma RV, Davisson RL (2004) Hypertension caused by angiotensin II infusion involves increased superoxide production in the central nervous system. Circ Res 95: 210-216.

17. Oliveira-Sales EB, Nishi EE, Carillo BA, Boim MA, Dolnikoff MS, et al. (2009) Oxidative stress in the sympathetic premotor neurons contributes to sympathetic activation in renovascular hypertension. Am J Hypertens 22: 484-492.

18. Campos RR, Oliveira-Sales EB, Nish EM, Boim MA, Dolnikoff MS, et al. (2011) The role of oxidative stress in renovascular hypertension Special Series: Stress and Hypertension. Clin Exp Pharmacol Physiol. doi: 10.1111/j.14401681.2010.05437.x.

19. Guyenet PG (2006) The sympathetic control of blood pressure. Nat Rev Neurosci 7: 335-346.

20. Braga VA, Paton JF, Machado BH (2007) Ischaemia-induced sympathoexcitation in spinalyzed rats. Neurosci Lett 415: 73-76.

21. Owsjannikow P (1871) Die tonischen und reflectorischencentren der gefassnerven. Ber Verh Saechs Wiss Leipzig Math Phys KI 23: 135-143.

22. Guertzenstein PG, Silver A (1974) Fall in blood pressure produced from discrete regions of the ventral surface of the medulla by glycine and lesions. $J$ Physiol 242: 489-503.

23. Feldberg W, Guertzenstein PG (1976) Vasodepressor effects obtained by drugs acting on the ventral surface of the brain stem. J Physiol 258: 337-355.

24. Lind RW, Swanson LW, Ganten D (1985) Organization of angiotensin
II immunoreactive cells and fibers in the rat central nervous system. An immunohistochemical Study. Neuroendocrinology 40: 2-24.

25. Allen AM, Chai SY, Sexton PM, Lewis SJ, Verberne AJ, et al. (1987) Angiotensin II receptors and angiotensin converting enzyme in the medulla oblongata. Hypertension 9: III198-205.

26. Li YW, Guyenet PG (1996) Angiotensin II decreases a resting K+ conductance in rat bulbospinal neurons of the $C 1$ area. Circ Res 78: 274-282.

27. Andreatta SH, Averill DB, Santos RA, Ferrario CM (1988) The ventrolatera medulla. A new site of action of the renin-angiotensin system. Hypertension 11: $\mid 163-166$.

28. Hirooka Y, Potts PD, Dampney RA (1997) Role of angiotensin II receptor subtypes in mediating the sympathoexcitatory effects of exogenous and endogenous angiotensin peptides in the rostral ventrolateral medulla of the rabbit. Brain Res 772: 107-114.

29. Ito S, Komatsu K, Tsukamoto K, Kanmatsuse K, Sved AF (2002) Ventrolatera medulla AT1 receptors support blood pressure in hypertensive rats. Hypertension 40: 552-559.

30. Braga VA, Burmeister MA, Zhou Y, Sharma RV, Davisson RL(2008) Selective ablation of AT1a receptors in rostral ventrolateral medulla (RVLM) prevents chronic angiotensin-II-dependent hypertension in part by reducing oxidant stress in this region. Hypertension 52: e36-e36.

31. Oliveira-Sales EB, Colombari DS, Davisson RL, Kasparov S, Hirata AE, et al. (2010) Kidney-induced hypertension depends on superoxide signaling in the rostral ventrolateral medulla. Hypertension 56: 290-296.

32. Hirooka Y (2008) Role of reactive oxygen species in brainstem in neural mechanisms of hypertension. Auton Neurosci 142: 20-24

33. Oliveira-Sales EB, Dugaich AP, Carillo BA, Abreu NP, Boim MA, et al. (2008) Oxidative stress contributes to renovascular hypertension. Am J Hypertens 21: 98-104.

34. Dugaich AP, Oliveira-Sales EB, Abreu NP, Boim MA, Bergamaschi CT, et al. (2011) Role of the rostral ventrolateral medulla in the arterial hypertension in chronic renal failure. Int J Hypertens 2010: 219358.

35. Czernichow S, Bertrais S, Blacher J, Galan P, Briançon S, et al. (2005) Effect of supplementation with antioxidants upon long-term risk of hypertension in the SU.VI.MAX study: association with plasma antioxidant levels. J Hypertens 23 2013-2018. 